\title{
Evaluation of Insulin Resistance Indices in Type 2 Diabetic Patients Treated with Different Anti-Diabetic Drugs
}

\author{
Mohammad-Ali Ghaffari ${ }^{1}$, Seyedeh-Arefeh Payami², Seyed-Peyman Payami' ${ }^{3}$, \\ Damoon Ashtary-Larky², Abdolrahim Nikzamir ${ }^{4}$, Ghorban Mohammadzadeh ${ }^{\text {** }}$ \\ ${ }^{1}$ Cellular and Molecular Research Center, Department of Clinical Biochemistry, School of Medicine, \\ Ahvaz Jundishapur University of Medical Sciences, Ahvaz, Iran \\ ${ }^{2}$ Department of Clinical Biochemistry, School of Medicine, Ahvaz Jundishapour University of Medical Science, \\ Ahvaz, Iran \\ ${ }^{3}$ Health Research Institute, Diabetes Research Center, Ahvaz Jundishapur University of Medical Sciences, \\ Ahvaz, Iran \\ ${ }^{4}$ Department of Clinical Biochemistry, School of Medicine, Shahid Beheshti University of Medical Science, \\ Tehran, Iran \\ ${ }^{5}$ Hyperlipidemia Research Center, Department of Clinical Biochemistry, Faculty of Medicine, \\ Ahvaz Jundishapur University of Medical Sciences, Ahvaz, Iran \\ Email: *mohammadzadeh@ajums.ac.ir
}

Received 31 December 2015; accepted 13 February 2016; published 16 February 2016

Copyright (C) 2016 by authors and Scientific Research Publishing Inc.

This work is licensed under the Creative Commons Attribution International License (CC BY). http://creativecommons.org/licenses/by/4.0/

c) (i) Open Access

\begin{abstract}
Clinically, determination of insulin resistance is important for diabetic patients. We evaluated the relationship among 20/(fasting C-peptide $\times$ fasting plasma glucose), HOMA-IR and QUICKI indices in type 2 diabetic patients. The study included 40 patients with type 2 diabetes. Patients divided into three groups based on their medication: metformin, metformin + glibenclamide and metformin + glitazone. Fasting blood sugar, and lipid profile were measured by enzymatic method, serum insulin, and C-peptide were measured by ELISA method. Insulin resistance was calculated by using of 20/(fasting C-peptide $\times$ fasting plasma glucose), HOMA-IR and QUICKI indices. There was no significant relationship between 20 /(fasting C-peptide $\times$ fasting plasma glucose) index and other parameters in all studied groups except QUICKI in metformin group showed a significant correlation with 20 /(fasting C-peptide $\times$ fasting plasma glucose $)$ index $(r=0.56$ and $p=0.03)$. There was a significant correlation between HOMA-IR and QUICKI indices in all studied groups. There was no significant relationship between 20 /(fasting C-peptide $\times$ fasting plasma glucose) index with other clinical parameters. On the other hand, our data strongly suggested a significant correlation between HOMA-IR and QUICKI indices in studied subjects with type 2 diabetes.
\end{abstract}

${ }^{*}$ Corresponding author.

How to cite this paper: Ghaffari, M.-A., Payami, S.-A., Payami, S., Ashtary-Larky, D., Nikzamir, A. and Mohammadzadeh, G. (2016) Evaluation of Insulin Resistance Indices in Type 2 Diabetic Patients Treated with Different Anti-Diabetic Drugs. Open Journal of Endocrine and Metabolic Diseases, 6, 95-101. http://dx.doi.org/10.4236/ojemd.2016.62013 
Keywords

Type 2 Diabetes, Insulin Resistance, HOMA-IR, QUICKI, 20/(Fasting C-Peptide × Fasting Plasma Glucose)

\section{Introduction}

The prevalence of diabetes is increasing in the worldwide [1]. It is highly prevalent in developing countries including Iran which estimated about 2\% - 10\% prevalence in 2008 [2].

Insulin resistance which defined by impaired ability of insulin to stimulate glucose utilization is a major characteristic of diabetic patients [3]-[5]. Insulin resistance is closely associated with high blood pressure, obesity, coronary artery disease, dyslipidemia, metabolic syndrome and other disorders that characterized as metabolic syndrome [5]. The diagnosis of insulin resistance in humans is important for epidemiological, clinical, basic and applied scientific research and clinical trials. Direct and indirect methods are commonly used for this purpose. Most methods depend on static analysis of glucose and insulin while other methods are related to the dynamic tests. Each of these methods has advantages and limitations distinctively. Clinically, hyperinsulinemic-euglycemic clamp is the gold-standard method to assessment of insulin sensitivity. The main limitations of this method include long time, expensiveness, and require experienced operators to manage the technical problems [6].

Alternative indices for insulin sensitivity measurement are obtained from the dynamic tests such as oral glucose tolerance test (OGTT) and meal tolerance test (MTT) [7]. Since OGTT in patients with severe diabetes can cause hyperglycemia, the homeostasis model assessment of insulin resistance (HOMA-IR) index is widely used in medicine for clinical studies. HOMA-IR is a model that uses the static concentrations of fasting glucose and insulin for determination of insulin resistance and pancreatic beta-cell function [8]. The validity of HOMA-IR index is lower in patients with low body mass index (BMI), low-activity of beta cells and high levels of blood glucose [9].

Quantitative Insulin Sensitivity Check Index (QUICKI) is another insulin sensitivity index, which has better correlation with glucose clamp technique, compared with other indicators such as the minimal model and HOMA. On the other hand, the relationship between QUICK and glucose clamp technique declines in non-obese patients compared with obese diabetic individuals [10]. Since insulin and C-peptide excreted from beta cells with the equal concentration [11] and the liver couldn't remove C-peptide. Thus, linear correlation between metabolic clearance rate of C-peptide and its plasma level could be expected [12]. Therefore, it is evident that the circulating level of C-peptide shows a more accurate reflection of pancreatic secretion compared with insulin levels [13].

According to above informations, a new index introduced based on the amount of C-peptide and insulin resistance in Japanese patients with type 2 diabetes. 20/(fasting C-peptide $\times$ fasting plasma glucose) is a simple and effective index for insulin resistance that compared with HOMA-IR and ISI in Japanese patients with type 2 diabetes. In particular, this index has shown a strong relationship with Glucose Infusion Rate (GIR) compared with HOMA-IR in patients with mild insulin resistance. Furthermore, GIR may be predicted by the index [14].

Therefore, in this study, in order to express the importance of new index for diagnosis of insulin resistance in type 2 diabetes patients, we evaluated the relationship among 20/(fasting C-peptide $\times$ fasting plasma glucose), HOMA-IR and QUICKI indices in type 2 diabetic patients who take certain hypoglycemic medications.

\section{Materials and Methods}

\subsection{Study Population}

The study population included 40 patients with type 2 diabetes mellitus whom attended at the diabetic clinic of Ahvaz Golestan Hospital, Ahvaz Jundishapur University of medical Sciences, Ahvaz, Iran. Among of them, 15 patients take metformin, 15 patients take metformin + glibenclamide and 10 patients take metformin + Glitazone. Participates were men and women with body mass index more than $25 \mathrm{~kg} / \mathrm{m}^{2}$ and age from 35 to 65 years. Patients who received insulin or having renal disorders, cardiovascular disease, and uncontrolled thyroid disease were exclude from the study. Well-trained interviewers recorded sex, age, height, weight, body mass index 
(BMI), the histories of medication usage for diabetes, addiction from all participants. Body weight was measured to the nearest $0.1 \mathrm{~kg}$ and the height to the nearest $0.1 \mathrm{~cm}$ using a standard balance and stadiometer (Seca, Germany). The waist circumference was measured according to WHO guideline midway between the lowest rib and the iliac crest with a flexible anthropometric tape [15].

\subsection{Blood Sampling}

All subjects referred to the laboratory at the same time of day (between 08:30 and 09:00 AM) after an overnight $(10-12 \mathrm{~h}$ ) fast, having consumed no alcohol or caffeine for at least $24 \mathrm{~h}$ nor exercised within the previous $48 \mathrm{~h}$. $5 \mathrm{ml}$ venous blood samples were collected into without anticoagulant containing tubes from all patients. The blood samples were allowed to clot at room temperature and then serum separated was stored at $-70^{\circ} \mathrm{C}$ for future use. Fasting bloodsugar was determined by glucose oxidase method (Pars Azmoon Co., Tehran, Iran). Fating lipid profile including total cholesterol, triglycerides, and high-density lipoprotein-cholesterol (HDL-C) were measured by enzymatic methods using commercial available kits ((Pars Azmoon Co., Tehran, Iran). Low-density lipoprotein-cholesterol (LDL-C) was estimated indirectly using the Friedewald formula (LDL cholesterol = total cholesterol-HDL cholesterol $+1 / 5$ triglycerides) for subjects with serum TG level less than $400 \mathrm{mg} / \mathrm{ml}$. Serum level of insulin and C-peptide were measured by enzyme-linked immunosorbent assay using commercially available human ELISA kit (Monobind Inc., Lake Forest, CA, USA) after serum samples were thawed at room temperature.

\subsection{Insulin Resistance Calculation}

HOMA-IR, QUICKI and 20/(fasting C-peptide $\times$ fasting plasma glucose) index were calculated using the following formula:

$$
\begin{aligned}
\text { HOMA-IR }= & {[\text { fasting insulin }(\mu \mathrm{U} / \mathrm{ml})] \times[\text { fasting glucose }(\mathrm{mmol} / \mathrm{L})] / 22 / 5 } \\
\text { QUICKI }=1 /[ & \log (\text { fasting insulin }(\mu \mathrm{U} / \mathrm{ml}))+\log (\text { fasting glucose }(\mathrm{mg} / \mathrm{dL}))] \\
& 20 /(\text { fasting C-peptide } \times \text { fasting plasma glucose })
\end{aligned}
$$

Insulin resistance defined as HOMA-IR above 2.6, QUICKI less than 0.33, 20/(fasting C-peptide $\times$ fasting plasma glucose) less than 5 and 5 - 10 as mild insulin resistance [5] [14] [16] [17].

\subsection{Statistical Analysis}

All statistical analyses have been performed using SPSS version 20.0 software (SPSS, Inc, Chicago IL, USA). All data are expressed as mean value \pm Standard Error of Means (S.E.M). Mean comparisons were made using one-way analysis of variance (ANOVA) followed by Tukey's post hoc test. The level of significance was adjusted at $\mathrm{P}<0.05$.

\section{Results}

Mean values of age, weight, BMI, abdominal circumference, total cholesterol, triglycerides, HDL, LDL, fasting glucose, fasting insulin, C-peptide, HOMA-IR, QUICKI and (fasting C-peptide $\times$ fasting plasma glucose)/20 indices are presented in Table 1. According to the calculated indices in the three studied groups, all patients have been shown insulin resistance. The relationship between (fasting C-peptide $\times$ fasting plasma glucose)/20 index and clinical parameters have been shown in Table 2. There are no significant relationships between (fasting C-peptide $\times$ fasting plasma glucose)/20 index and other parameters in all three studied groups except QUICKI index in the patients that receiving metformin showed a significant correlation with (fasting C-peptide $\times$ fasting plasma glucose $) / 20$ index $(r=0.56, p=0.03)$. The relationship between HOMA-IR and QUICKI indices are shown in Table 3 and illustrate in Figure 1. According to these result, there was a significant correlation between these two indices in the three studied groups.

\section{Discussion}

The goal of this study was to identify reliable simple method for the diagnosis of insulin resistance in type 2 diabetic patients. For this purpose, the relationship between index 20/(fasting C-peptide $\times$ fasting plasma glucose) 
Table 1. Basic characteristic of the study subjects.

\begin{tabular}{cccc}
\hline & Metformin & Metformin + Glibenclamide & Metformin + Glitazone \\
\hline Age (year) & $48.53 \pm 1.8$ & $47.8 \pm 2.5$ & $49.5 \pm 3.1$ \\
Weight (kg) & $80.86 \pm 4.9$ & $85.66 \pm 2.6$ & $85.87 \pm 5.4$ \\
BMI (kg/m $\left.{ }^{2}\right)$ & $28.87 \pm 0.9$ & $30.29 \pm 0.7$ & $32.43 \pm 1.5$ \\
Waist Circumference (cm) & $101.0 \pm 1.3$ & $102.66 \pm 2.01$ & $106.4 \pm 3.4$ \\
Total Cholesterol (mg/dl) & $158.80 \pm 6.2$ & $181.07 \pm 10.6$ & $174.80 \pm 9.3$ \\
Triglyceride (mg/dl) & $201.07 \pm 7.2$ & $184.6 \pm 9.4$ & $191.2 \pm 10.2$ \\
HDL Cholesterol (mg/dl) & $39.53 \pm 1.6$ & $39.53 \pm 1.6$ & $41.5 \pm 2.2$ \\
LDL Cholesterol (mg/dl) & $115.07 \pm 6.3$ & $131.33 \pm 9.9$ & $137.6 \pm 6.4$ \\
FBS (mg/dl) & $114.00 \pm 4.3$ & $115.00 \pm 6.6$ & $140.00 \pm 9.07$ \\
Fasting Insulin ( $\mu \mathrm{U} / \mathrm{ml})$ & $14.84 \pm 1.4$ & $14.7 \pm 1.4$ & $13.03 \pm 2.3$ \\
Fasting C-peptide (ng/dl) & $2.69 \pm 0.2$ & $3.02 \pm 0.2$ & $3.4 \pm 0.1$ \\
HOMA Index & $4.8 \pm 0.4$ & $4.3 \pm 0.4$ & $4.5 \pm 0.8$ \\
QUICKI Index & $0.3 \pm 0.003$ & $0.3 \pm 0.007$ & $0.31 \pm 0.01$ \\
20/(fasting C-peptide $\times$ FPG) & $4.2 \pm 0.7$ & $3.5 \pm 0.3$ & $2.4 \pm 0.1$ \\
\hline
\end{tabular}

Data are presented as mean \pm S.E.M; HOMA-IR: homeostasis model assessment of insulin resistance; QUICKI = quantitative insulin sensitivity check index; BMI = body mass index; FBS =fasting blood sugar; FPG = fasting plasma glucose.

Table 2. Relationship between 20/(fasting C-peptide $\times$ fasting plasma glucose) index with other clinical parameters.

\begin{tabular}{cccccccc}
\hline & \multicolumn{2}{c}{ Metformin } & \multicolumn{2}{c}{ Metformin + Glibenclamide } & \multicolumn{3}{c}{ Metformin + Glitazone } \\
\cline { 2 - 8 } & $\mathrm{r}$ & $\mathrm{P}$ & $\mathrm{r}$ & $\mathrm{P}$ & $\mathrm{r}$ & $\mathrm{P}$ \\
HOMA-IR & 0.05 & 0.056 & -0.35 & 0.19 & -0.52 & 0.11 \\
QUICKI & 0.56 & 0.03 & -0.32 & 0.24 & 0.59 & 0.07 & 0.37 \\
BMI $\left(\mathrm{kg} / \mathrm{m}^{2}\right)$ & 0.24 & 0.38 & -0.09 & 0.72 & -0.31 & 0.35 \\
Waist Circumference $(\mathrm{Cm})$ & 0.23 & 0.39 & -0.06 & 0.81 & -0.33 & 0.35 \\
\hline
\end{tabular}

$\mathrm{r}=$ Pearson correlation coefficient; ${ }^{*} \mathrm{P}<0.05$ indicates significant difference. HOMA-IR: homeostasis model assessment of insulin resistance; QUICKI = quantitative insulin sensitivity check index; BMI = body mass index.

Table 3. Relationship between HOMA-IR and QUICKI indices.

\begin{tabular}{|c|c|c|c|c|c|c|}
\hline & \multicolumn{6}{|c|}{ HOMA-IR } \\
\hline & \multicolumn{2}{|c|}{ Metformin group } & \multicolumn{2}{|c|}{ Metformin + Glibenclamide group } & \multicolumn{2}{|c|}{ Metformin + Glitazone group } \\
\hline & r & $\mathrm{P}$ & $\mathrm{r}$ & $\mathrm{P}$ & $\mathrm{r}$ & $\mathrm{P}$ \\
\hline QUICKI & -0.97 & $<0.001$ & -0.87 & $<0.001$ & -0.84 & 0.002 \\
\hline
\end{tabular}

$\mathrm{r}$ = Pearson correlation coefficient; HOMA-IR: homeostasis model assessment of insulin resistance; QUICKI = quantitative insulin sensitivity check index.

with HOMA-IR and QUICKI indices was investigated. Based on our result, there was no correlation between the index 20/(fasting C-peptide ×fasting plasma glucose) with HOMA-IR and QUICKI in all participated patients except in the metformin group. Clinically, HOMA-IR is simple, and widely used to identify of insulin resistance. However, HOMA-IR is of limited use in some patients with a lower BMI, decreased $\beta$ cell function, and high fasting glucose levels [9]. In Japanese and Asian population often show reduced $\beta$ cell function, HOMA-IR is inappropriate in these populations. Our results revealed that there were a strongly correlated between HOMA-IR and QUICKI in all studied patients. Katz et al. reported a significant correlation between QUICKI with HOMA-IR and glucose clamp. Though, relation between QUICKI and glucose clamp is lower in non-obese subjects without diabetes than in obese patients with type 2 diabetes mellitus [10]. It has been demonstrated, insulin and C-peptide co-secreted from the pancreas in an equimolar ratio into the blood stream. Unlike insulin, C-peptide is not cleared by the liver, and has a longer half-life compared to the insulin [11]. Ohkura 


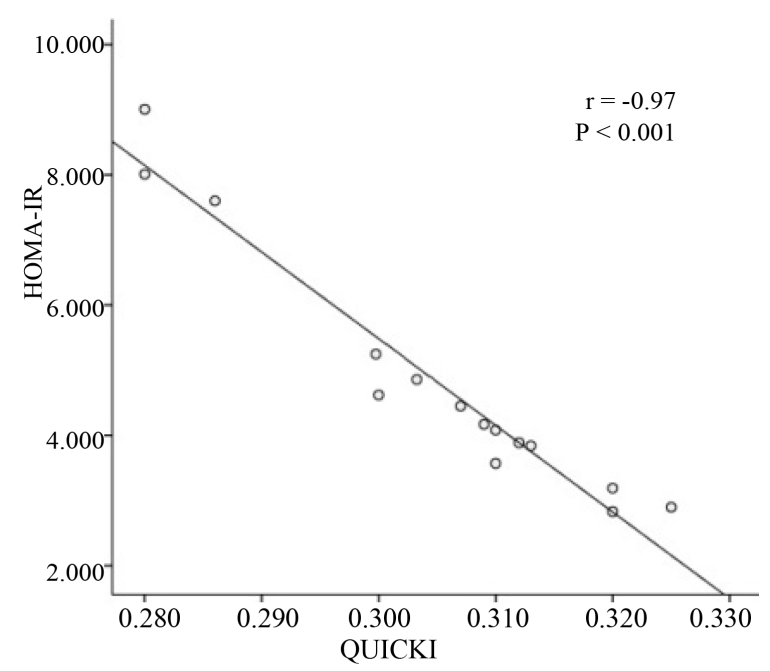

(a)

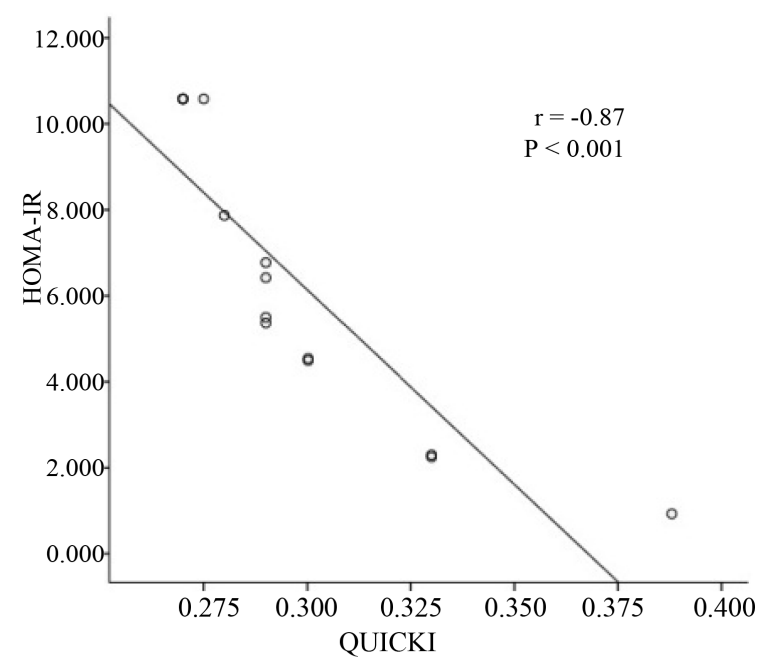

(b)

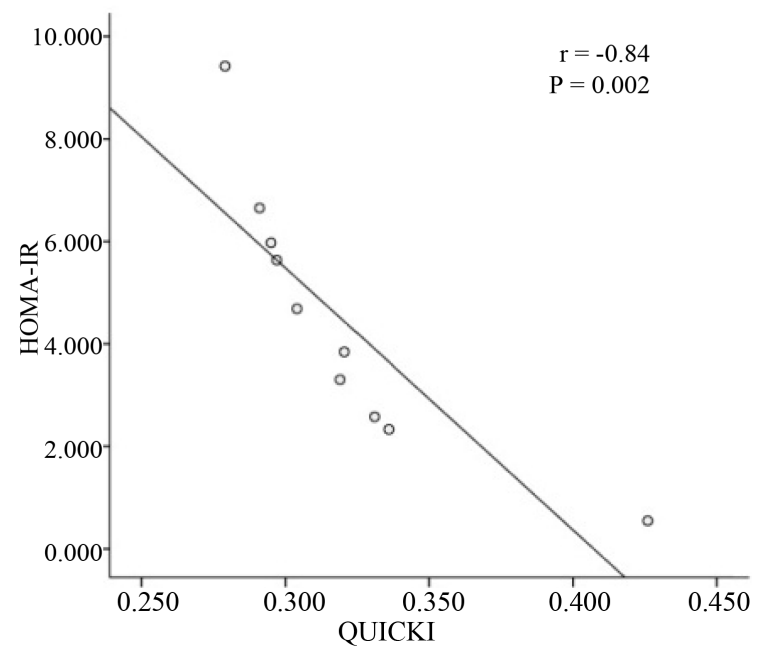

(c)

Figure 1. Relationship between HOMA-IR and QUICKI indices in metformin group (a), metformin + glibenclamide group (b) and metformin + glitazone group. 
et al. suggested an index consisting of the C-peptide levels will be better than an index based on insulin levels for evaluation of insulin resistance. They reported, index 20/(fasting C-peptide $\times$ fasting plasma glucose) was more strongly correlated with GIR than HOMA-IR among patients with mild insulin resistance. Furthermore, it is possible to predict GIR by determining 20/(fasting C-peptide $\times$ fasting plasma glucose). This results show that plasma C-peptide levels better reproduce insulin bioactivity in skeletal muscle, while the glucose clamp technique reflects insulin resistance in skeletal muscle [14]. Our study had several limitations, including number of patients and no evaluation of correlation between indexes 20/(fasting C-peptide $\times$ fasting plasma glucose) and glucose clamp technique. Despite these limitations and no significant correlation was observed between studied indices, we think 20/(fasting C-peptide $\times$ fasting plasma glucose) index in Asian subjects including Iranian patients with type 2 diabetes mellitus didn't generally show hyperinsulinemia. Stratified diabetic patients based on drug medication have been performed just for removing the various effects of oral hypoglycemic agents on the insulin resistance indices.

Our results suggested that for comparing the clinical importance of 20/(fasting C-peptide $\times$ fasting plasma glucose) index with well-known indices for evaluation of insulin resistance indices in diabetic patients of different populations, several studies with greater number of patients are needed.

\section{Conclusion}

Although, there was no significant association between 20/(fasting C-peptide $\times$ fasting plasma glucose) index and other clinical parameters in the studied population. However, our results strongly suggested a significant correlation between HOMA-IR and QUICKI indices in studied subjects with type 2 diabetes.

\section{Acknowledgements}

This research project has been financially supported by Cellular and Molecular Research Center, Ahvaz Jundishapur University of Medical Sciences, Ahvaz, Iran (Grant No. CMRC-105).

\section{Conflict of Interests}

The authors declare that there is no conflict of interests regarding to the publication of the paper.

\section{References}

[1] Rashidi, H., Kasiri, A., Latifi, SM., Zaman, F., Shabazian, H. and Moravej, A. (2014) Comparison of Established Risk Factors among Type 2 Diabetic Patients with or without Retinopathy in Golestan Hospital, Ahvaz 2010. Open Journal of Endocrine and Metabolic Diseases, 4, 225-229. http://dx.doi.org/10.4236/ojemd.2014.410022

[2] Tol, A., Mohebbi, B., Sadeghi, R., Maheri, A. and Eshraghian, M.R. (2014) Determinants of Health-Promoting Behaviors among Type 2 Diabetic Patients: Voice of Iran. Open Journal of Endocrine and Metabolic Diseases, 4, 219-224. http://dx.doi.org/10.4236/ojemd.2014.49021

[3] DeFronzo, R.A. and Ferrannini, E. (1991) Insulin Resistance: A Multifaceted Syndrome Responsible for NIDDM, Obesity, Hypertension, Dyslipidaemia, and Atherosclerotic Cardiovascular Disease. Diabetes Care, 14, 173-194. http://dx.doi.org/10.2337/diacare.14.3.173

[4] Zare Javid, A., Ashtary Larky, D., Alipour Khoshdel, M., Shariatifar, R. and Hosseini, S.A. (2014) Impact of ShortTerm Intake of Cinnamon on Serum Glucose and Lipid Profile in Patients with Type 2 Diabetes Mellitus. Journal of Applied Environmental and Biological Sciences, 4, 295-298.

[5] Himsworth, H.P. (1936) Diabetes Mellitus: Its Differentiation into Insulin-Sensitive and Insulin-Insensitive Types. The Lancet, 227, 127-130. http://dx.doi.org/10.1111/j.1464-5491.2011.3508.x

[6] Muniyappa, R., Lee, S., Chen, H. and Quon, M.J. (2008) Current Approaches for Assessing Insulin Sensitivity and Resistance in Vivo: Advantages, Limitations, and Appropriate Usage. American Journal of Physiology-Endocrinology and Metabolism, 294, 15-26. http://dx.doi.org/10.1152/ajpendo.00645.2007

[7] Matsuda, M. and DeFronzo, R.A. (1999) Insulin Sensitivity Indices Obtained from Oral Glucose Tolerance Testing: Comparison with the Euglycemic Insulin Clamp. Diabetes Care, 22, 1462-1470. http://dx.doi.org/10.2337/diacare.22.9.1462

[8] Matthews, D.R., Hosker, J.P., Rudenski, A.S., Naylor, B.A., Treacher, D.F. and Turner, R.C. (2005) Homeostasis Model Assessment: Insulin Resistance and Beta-Cell Function from Asting Plasma Glucose and Insulin Concentrations in Man. Diabetologia, 28, 412-419. http://dx.doi.org/10.1007/BF00280883 
[9] Kang, E.S., Yun, Y.S., Park, S.W., Kim, H.J., Ahn, C.W., Song, Y.D., et al. (2005) Limitation of the Validity of the Homeostasis Model Assessment as an Index of Insulin Resistance in Korea. Metabolism, 54, 206-211. http://dx.doi.org/10.1016/j.metabol.2004.08.014

[10] Katz, A., Nambi, S.S., Mather, K., Baron, A.D., Follmann, D.A., Sullivan, G. and Quon, M.J. (2000) Quantitative Insulin Sensitivity Check Index: A Simple, Accurate Method for Assessing Insulin Sensitivity in Humans. The Journal of Clinical Endocrinology and Metabolism, 85, 2402-2410.

[11] Eaton, R.P., Allen, R.C., Schade, D.S., Erickson, K.M. and Standefer, J. (1980) Prehepatic Insulin Production in Man: Kinetic Analysis Using Peripheral Connecting Peptide Behavior. The Journal of Clinical Endocrinology and Metabolism, 51, 520-528.

[12] Polonsky, K.S., Licinio-Paixao, J., Given, B.D., Pugh, W., Rue, P., Galloway, J., et al. (1986) Use of Biosynthetic Human C-Peptide in the Measurement of Insulin Secretion Rates in Normal Volunteers and Type I Diabetic Patients. Journal of Clinical Investigation, 77, 98-105. http://dx.doi.org/10.1172/JCI112308

[13] Greenbaum, C.J., Mandrup-Poulsen, T., McGee, P.F., Battelino, T., Haastert, B., Ludvigsson, J., et al. (2008) Type 1 Diabetes Trial Net Research Group; European C-Peptide Trial Study Group: Mixed-Meal Tolerance Test versus Glucagon Stimulation Test for the Assessment of Beta-Cell Function in Therapeutic Trials in Type 1 Diabetes. Diabetes Care, 31, 1966-1971. http://dx.doi.org/10.2337/dc07-2451

[14] Ohkura, T., Shiochi, H., Fujioka, Y., Sumi, K., Yamamoto, N., Matsuzawa, K., et al. (2013) 20/(Fasting C-Peptide × Fasting Plasma Glucose) Is a Simple and Effective Index of Insulin Resistance in Patients with Type 2 Diabetes Mellitus a Preliminary Report. Cardiovascular Diabetology, 12, 21. http://dx.doi.org/10.1186/1475-2840-12-21

[15] World Health Organization (1987) Measuring Obesity-Classification and Description of Anthropometric Data. Report on a WHO Consultation of the Epidemiology of Obesity. Warsaw 21-23 October 1987. Copenhagen: WHO, 1989. Nutrition Unit Document, EUR/ICP/NUT 123.

[16] Kostandi, I., Bahgat, M., Zayed, N. and Rashed, L. (2011) Assessment of Insulin Resistance and Insulin Growth Factor-1 in Egyptian Patients with Chronic Hepatitis C. Open Journal of Endocrine and Metabolic Diseases, 1, 1-8. http://dx.doi.org/10.4236/ojemd.2011.11001

[17] Borai, A., Livingstone, C., Kaddam, I. and Ferns, G. (2011) Selection of the Appropriate Method for the Assessment of Insulin Resistance. BMC Med Res Methodology, 11, 158. 